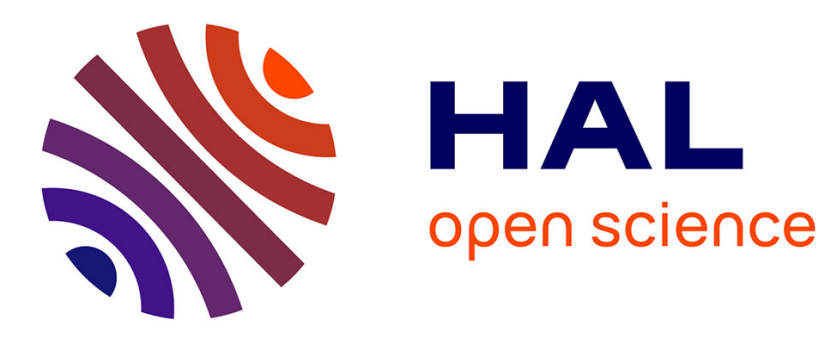

\title{
Sizing methodology based on design of experiments for freshwater and electricity production from multi-source renewable energy systems
}

Malek Zaibi, Habib Cherif, Gérard Champenois, Bruno Sareni, Xavier Roboam, Jamel Belhadj

\section{To cite this version:}

Malek Zaibi, Habib Cherif, Gérard Champenois, Bruno Sareni, Xavier Roboam, et al.. Sizing methodology based on design of experiments for freshwater and electricity production from multi-source renewable energy systems. Desalination, 2018, 446, pp.94-103. 10.1016/j.desal.2018.08.008 . hal01946152

\section{HAL Id: hal-01946152 \\ https://hal.science/hal-01946152}

Submitted on 5 Dec 2018

HAL is a multi-disciplinary open access archive for the deposit and dissemination of scientific research documents, whether they are published or not. The documents may come from teaching and research institutions in France or abroad, or from public or private research centers.
L'archive ouverte pluridisciplinaire HAL, est destinée au dépôt et à la diffusion de documents scientifiques de niveau recherche, publiés ou non, émanant des établissements d'enseignement et de recherche français ou étrangers, des laboratoires publics ou privés. 


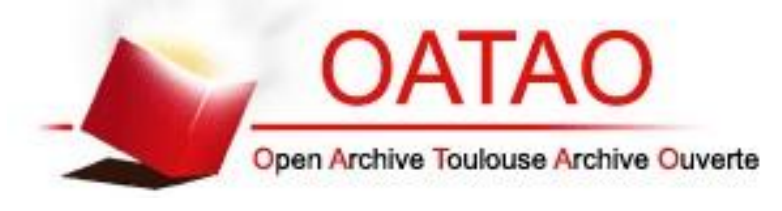

Open Archive Toulouse Archive Ouverte

OATAO is an open access repository that collects the work of Toulouse researchers and makes it freely available over the web where possible

This is an author's version published in: http://oatao.univ-toulouse.fr/21271

\section{Official URL:}

https://doi.org/10.1016/j.desal.2018.08.008

\section{To cite this version:}

Zaibi, Malek and Cherif, Habib and Champenois, Gérard and Sareni, Bruno and Roboam, Xavier and Belhadj, Jamel Sizing methodology based on design of experiments for freshwater and electricity production from multi-source renewable energy systems. (2018) Desalination, 446. 94-103. ISSN 0011-9164

Any correspondence concerning this service should be sent to the repository administrator: tech-oatao@listes-diff.inp-toulouse.fr 


\title{
Sizing methodology based on design of experiments for freshwater and electricity production from multi-source renewable energy systems
}

\author{
Malek Zaibi $^{\mathrm{a}, \mathrm{c}}$, Habib Cherif ${ }^{\mathrm{c}}$, Gérard Champenois ${ }^{\mathrm{a}, *}$, Bruno Sareni $^{\mathrm{b}}$, Xavier Roboam ${ }^{\mathrm{b}}$, \\ Jamel Belhadj ${ }^{\mathrm{c}}$ \\ a Université de Poitiers, LIAS-ENSIP, France \\ ${ }^{\mathrm{b}}$ Université de Toulouse, LAPLACE-INP-ENSEEIHT, France \\ ${ }^{\mathrm{c}}$ Université de Tunis EL Manar, LSE-ENIT, Tunisia
}

Keywords:

Optimal design

Design of experiments

Meta-model

Renewable energy

Isolated region

\begin{abstract}
A B S T R A C T
In remote areas, the vital need is production of drinking water and the provision of electrical energy for housing. Often the only sources of energy are based on renewable energies with storage to create a local micro-network. This paper investigates the optimal design of embodied energy for water treatment by reverse osmosis, coming from brackish water $(6 \mathrm{~g} / \mathrm{l})$ and with a double storage that is done in a drinking water tank and in batteries for electricity. Taking account wind and photovoltaic potentials in such system for assessing its performance implies its simulation over long periods of time. This can drastically increase the CPU time cost related to the design step, especially if the system energy management and sizing are sequentially optimized into a two-level optimization process. In order to solve this problem and accelerate the system simulation, meta-models are used for representing the system constraints and objectives. These meta-models are built by the design of experiments method. From realistic data, the results of this paper show that the contribution of the meta-models divides by two or three the design time by obtaining values of the sizing parameters close to the dynamic simulator depicting the real operation of the whole system.
\end{abstract}

\section{Introduction}

Around the world, large-scale development of renewable energy technologies is giving new opportunities to regions that lack fresh water and electricity. Even regions rich in fossil energy are beginning to worry about energy efficiency, long-term sustainability and environmental friendliness [1]. Today, many papers deal with systems for generating electrical energy from renewable energies: development of structures and their optimal sizing based on environmental and/or economical considerations $[2,3]$. In this regard, it is necessary to select and configure the optimal life cycle calibration of all hybrid renewable energy systems to operate at minimum economic and energy costs (embodied energy) while maintaining reliability of the system. From electrical energy, often the reverse osmosis process is used, because the need is to supply booster pumps and to fill tanks [4,5]. But intermittent renewable sources require the establishment of storage elements and/or mixing several sources. Many papers have already been published in this context. A study in Australia shows, when the distribution network is present, adding a wind turbine, PV and not using batteries reduces the financial cost of water production [6]. Another in Iran, on a remote site not really favorable for the wind turbine, shows that it is more profitable to use only PV with batteries [7]. Thus, the context of the site is a very important factor in the choice of the structure of the freshwater production system.

Regarding the design, sizing and optimization of the power systems based on renewable energy sources, several approaches are proposed using different indicators and configurations. For hybrid wind-solar power systems, linear programming techniques [8,9], pattern search based on SMCS (Sequential Monte Carlo Simulation) [10], particle swarm optimization algorithm [11], bees algorithm [12] have been applied under economic and technical indicators. An optimal sizing using a linear programming of photovoltaic power plants based on the optimal participation in electricity markets has been developed in Ref. [13]. In Ref. [14], a method employs the genetic algorithm to reduce the total cost of an offshore wind farm by optimizing its architectural design. A recent paper compares several optimization approaches for reverse osmosis water desalination system with solar and wind hybrid energy [15]. A robust solution method proposed in Ref. [16] used DIgSILENT Power Factory software for optimally coordinating a mix of distributed energy resources in the presence of high wind penetration to

\footnotetext{
* Corresponding author at: Université de Poitiers, LIAS-ENSIP, Bat. B25, 2 rue Pierre Brousse, TSA 41105, Poitiers Cedex 9 F86073, France.

E-mail address: gerard.champenois@univ-poitiers.fr (G. Champenois).
} 


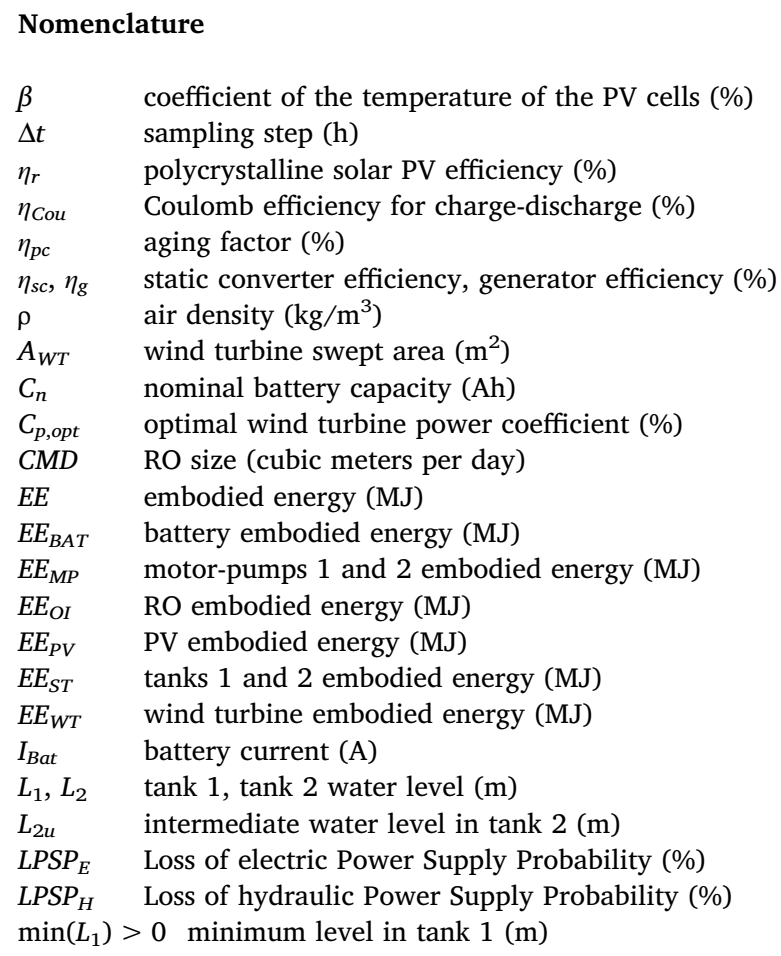

NOCT nominal operating cell temperature $\left({ }^{\circ} \mathrm{C}\right)$

$P_{1}, P_{2} \quad$ motor-pumps 1,2 electric power (W)

$P_{r} \quad$ pump 1 pressure (bar)

$P_{\text {Bat }} \quad$ battery power (W)

$P_{C V 1}, P_{C V 2}$ converter power of motor-pumps 1 and 2 (V.A)

$P_{\text {Diff }} \quad=P_{P V}+P_{W T}-P_{\text {load-elec }}(\mathrm{W})$

$P_{\text {load-elec }}$ electric power consumed (W)

$P_{P V} \quad$ optimal photovoltaic generator power (W)

$P_{W T} \quad$ wind turbine power (W)

$Q_{1}, Q_{2} \quad$ motor-pumps 1,2 flow rate $\left(\mathrm{m}^{3} / \mathrm{h}\right)$

$Q_{2 p} \quad$ freshwater flow rate $\left(\mathrm{m}^{3} / \mathrm{h}\right)$

$Q_{2 r} \quad$ concentrate flow rate $\left(\mathrm{m}^{3} / \mathrm{h}\right)$

$Q_{\text {load-hydrau }}$ water consumed $\left(\mathrm{m}^{3} / \mathrm{h}\right)$

$R_{r} \quad$ recovery rate (\%)

$S_{1}, S_{2} \quad$ tank 1, tank 2 surface area $\left(\mathrm{m}^{2}\right)$

SOC state of charge (\%)

$S_{u} \quad$ intermediate state of charge (\%)

$T_{a} \quad$ ambient temperature $\left({ }^{\circ} \mathrm{C}\right)$

$T_{c} \quad$ temperature of the PV cells $\left({ }^{\circ} \mathrm{C}\right)$

$V_{\text {Bat }} \quad$ voltage battery (V)

$V$ wind $\quad$ wind speed $(\mathrm{m} / \mathrm{s})$

DOE design of experiments

PV photovoltaic panel

RO reverse osmosis membrane

WT wind turbine simultaneously minimize operating costs and maximize the utilization of wind turbine generation.

Many sizing optimization publications optimize life cycle cost [17,9-13] and take into account weather conditions (wind speed, solar radiation and temperature) for one year $[5-7,12,17,18]$. In this paper, modeling is done on the amount of embodied energy ( $E E$ ) for the life cycle of each element of the system, from meteorological records (wind speed, solar radiation, and temperature) over a year and for isolated sites. Sizing optimization is always done using optimization algorithms that require a high CPU time for the implementation of the optimization algorithms that depends on the modeling used to represent the operation of the system. Some authors use a dynamic simulator including the physical equations of each element, weather data and load equations. The resolution is done with a computing step of several minutes or hours. Thus, one year data resolution represents several thousand computation loops for one parameter vector. So, global optimization can take a CPU time of several days if the system is a bit complex. The goal of this paper is to propose a new modeling based on meta-models that replaces the dynamic simulator with an equation vector that links the outputs with the parameter vector in the optimization process. The quality of the meta-models becomes a crucial point for the quality of the results and it is also important to minimize the time to establish these meta-models. Early experiments have shown that the Design Of Experiments (DOE) approach can give good results. The application of the DOE method in several areas has been discussed by many authors $[19,20]$, but only a very few attempts have been made to integrate the DOE in systemic design. In a recent study, a modeling approach is presented by Ref. [17] to size an autonomous multi-source system with battery storage and a diesel generator. It is also used in Ref. [21] for a photovoltaic/wind/Battery energy system with storage to investigate a meta-model by hybrid spline interpolation. This study contributes to integrate a sizing methodology with DOE to optimize a freshwater and electricity production by multi-source renewable energy systems located in remote areas.

This paper gathers the papers already made in this area by the same authors by presenting the complete study with the results obtained and which integrates a new modeling of the reverse osmosis unit with its motor pump for a salinity of the water: $6 \mathrm{~g} / \mathrm{l}$ (brackish water from southern Tunisia (see Appendix A)). This last model uses only one parameter, which is the cubic meter per day (CMD), to limit the number of parameters in order to reduce the complexity of the system. The paper is organized as follows: after the Introduction, Section 2 describes the system with its modeling, presents the methodology to realize the optimization by implementing a dynamic simulator or meta-models. Section 3 shows the results and discusses the results obtained. The paper ends with a conclusion, one appendix and the bibliographic references.

\section{Description and methodology}

\subsection{System description}

\subsubsection{Architecture}

The electricity acquired from photovoltaic panels (PV) wind turbines (WT) will be used to feed the motor-pumps of a hydraulic process (water pumping and reverse osmosis desalination unit) and other electrical house loads. The system has two types of storage: battery energy storage and hydraulic storage in water tanks (brackish water storage and freshwater storage). The global architecture of the system, shown in Fig. 1, corresponds to the application described for the isolated areas. The different subsystems are coupled to the DC bus with different converters (DC/DC, AC/DC or DC/AC).

The hydraulic loads are composed of a first motor-pump 1 used to pump brackish water from well and to store it in a first tank and a second motor-pump supplied by the brackish water $(6 \mathrm{~g} / 1$ (see Appendix A)) to the Reverse Osmosis (RO) desalination unit to produce freshwater. This freshwater is stored in a second tank without pumping.

\subsubsection{Power and water flow models}

This part is devoted to the power and water flow models of the investigated system. In the context of optimizing the size of the system, it is important to specify all energy models with significant expressions to reduce the running time of the optimization program. For all renewable energy generator, the maximum power is taken account in the 


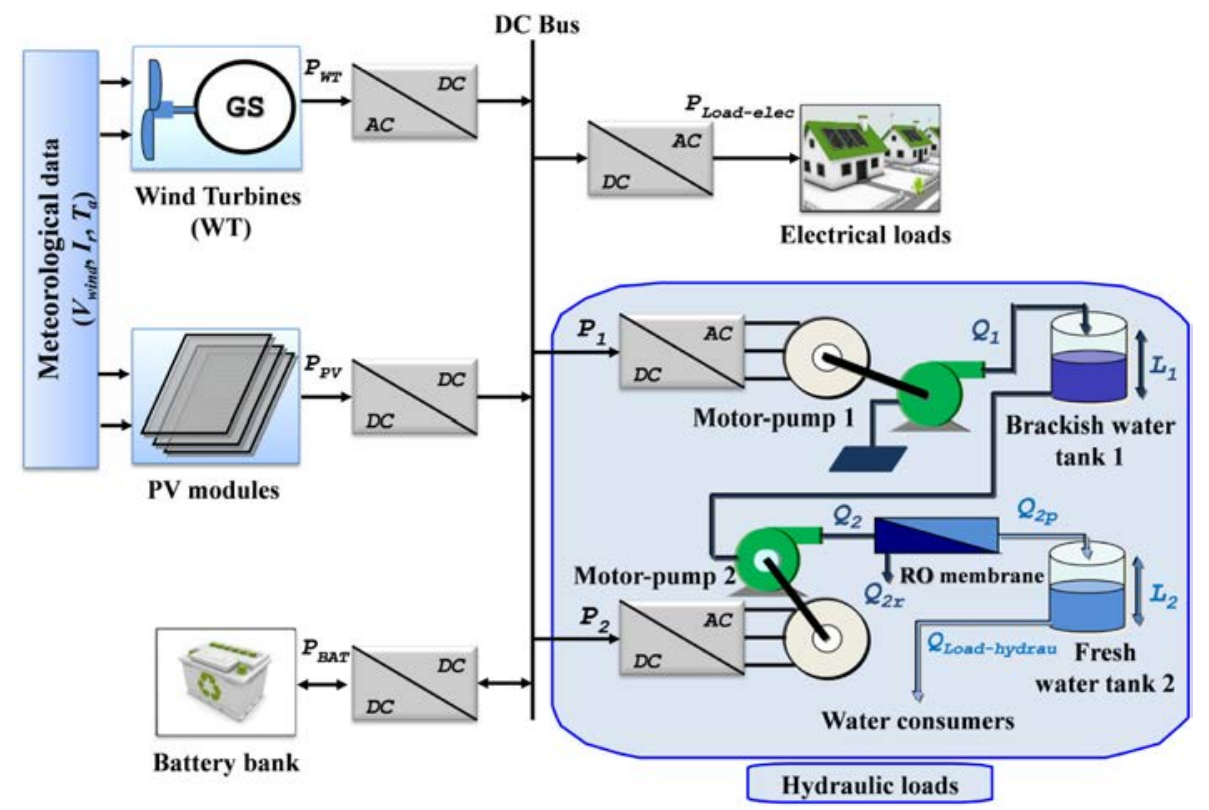

Fig. 1. The global system architecture.

formulas. That means the MPPT algorithm (maximum power point tracking) is considered as perfect.

2.1.2.1. Turbine model. The optimal wind turbine power (with MPPT) versus time $P_{W T}(t)$ has the following expression [22,23]:

$P_{W T}(t)=\frac{1}{2} \cdot \eta_{s c} \cdot \eta_{g} \cdot C_{p, o p t} \cdot \rho \cdot A_{W T} \cdot V_{\text {wind }}^{3}(t)$

with

$\eta_{s c}, \eta_{g} \quad$ static converter efficiency, generator efficiency,

$C_{p \text {,opt }} \quad$ optimal wind turbine power coefficient (i.e. corresponding to a perfect maximum point tracker),

$\rho \quad$ air density $\left(\mathrm{kg} / \mathrm{m}^{3}\right)$,

$A_{W T} \quad$ wind turbine swept area $\left(\mathrm{m}^{2}\right)$,

$V_{\text {wind }}(t)$ wind speed versus time $\left.(\mathrm{m} / \mathrm{s})\right)$.

2.1.2.2. Photovoltaic generator model. The optimal photovoltaic generator power (with MPPT) versus time $P_{P V}(t)(\mathrm{W})$ is proportional to the panel area $A_{P V}\left(\mathrm{~m}^{2}\right)$ and the solar irradiation versus time $I_{r}(t)(\mathrm{W} /$ $\mathrm{m}^{2}$ ), and depends on total efficiency versus time $\eta_{t}(t)$ [24,25]:

$P_{P V}(t)=\eta_{t}(t) \cdot A_{P V} \cdot I_{r}(t)$

with

$\eta_{t}(t)=\eta_{r} \cdot \eta_{p c} \cdot \eta_{s c} \cdot\left(1-\beta \cdot\left(T_{c}(t)-N O C T\right)\right.$

with

$\eta_{r} \quad$ polycrystalline solar PV efficiency (value taken: $13 \%$ ),

$\eta_{p c} \quad$ aging factor,

$\eta_{s c} \quad$ static converter efficiency,

$\beta \quad$ coefficient of the temperature of the PV cells $(0.004$ to $0.006\left({ }^{\circ} \mathrm{C}^{-1}\right)$,

NOCT nominal operating cell temperature,

$T_{c}(t)$ temperature of the PV cells versus time $\left({ }^{\circ} \mathrm{C}\right)$. with the expression of $T_{c}$ [26]:

$T_{c}(t)=30+0.0175 \cdot\left(I_{r}(t)-300\right)+1.14 \cdot\left(T_{a}(t)-25\right)$

$T_{a}(t) \quad$ ambient temperature versus time $\left({ }^{\circ} \mathrm{C}\right)$.
2.1.2.3. Electrical battery model. For the integration of the battery in the dynamic simulator, the most simple model is a constant internal voltage $E_{0}$ with a constant internal resistance $r_{\text {Bat }}$ [27]:

$V_{\text {Bat }}(t)=E_{0}-r_{\text {Bat }} I_{\text {Bat }}(t)$

$P_{\text {Bat }}(t)=V_{\text {Bat }}(t) \cdot I_{\text {Bat }}(t)$

where $I_{B a t}(t)$ and $P_{B a t}(t)$ are the battery current and power versus time $(t)$.

The state of charge evolution versus time $\operatorname{SOC}(t)$ of the battery depends on the battery current versus time $I_{B a t}(t)$ :

$\operatorname{SOC}(t)=\operatorname{SOC}(t-\Delta t)+\eta_{\text {Cou }} \cdot \frac{I_{\text {Bat }}(t) \cdot \Delta t}{C_{n}}$

where $\Delta t(\mathrm{~h})$ denotes the sampling step, $C_{n}$ : nominal battery capacity (Ah), $\eta_{\text {Cou }}$ : Coulomb efficiency for charge-discharge. Taking account the battery lifetime implies the SOC to stay into two technological limits; high and low according the following equations:

$S O C_{\min } \leq S O C(t) \leq S O C_{\max }$

with

$S O C_{\min }, S O C_{\max }$ minimal and maximal states of charge respectively.

2.1.2.4. Drawing water pump. Centrifugal pumps, with induction motor, are commonly used for pumping water from well. In this case, the motor-pump 1 is powered by three-phase power at fixed frequency for obtaining fixed speed, because the load law pressure $\left(P_{r}\right)$ vs flow rate $\left(Q_{1}\right)$ is almost constant and a variable speed would lead to a less energy efficiency. The design parameter is the electric power $P_{1}$ consumed by the motor-pump 1 . So, it is necessary to develop a equation linking the flow rate $Q_{1}$ with the electric power $P_{1}$.

From GRUNDFOS manufacturer pump datasheets and with the specifications of the hydraulic system, the range of pumps CRN 3 is the good choice. With the help of WinCAPS software [28,29], it allows us to calculate different operating points depending on the hydraulic load for the different pump sizes. Fig. 2 shows hydraulic data (pressure vs flow rate) for five sizes of the CRN3 pump type. The intersection of these five curves with the hydraulic load curve gives the five operating points (A to E). 


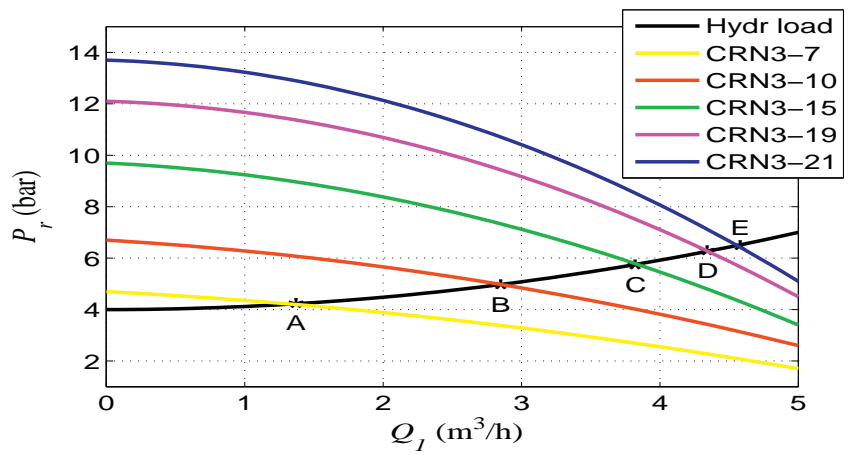

Fig. 2. Pressure vs flow $Q_{1}$ rate for CRN 3 (GRUNDFOS-pumps) and the hydraulic load.

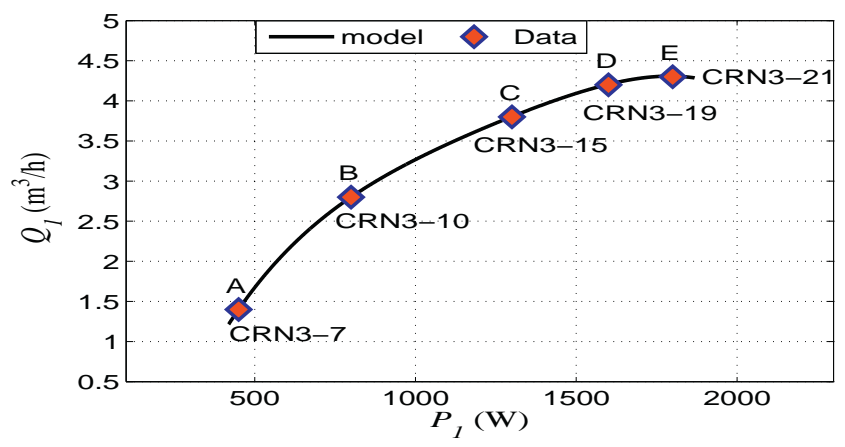

Fig. 3. Flow rate $Q_{1}$ vs electric power $P_{1}$ for CRN 3 operating points and the $Q_{1}$ vs $P_{1}$ model (9).

WinCAPS software also allows calculating the electric power of these five operating points. With "curve fitting tool" of Matlab, a polynomial model (fourth degree) can depict these five operating points. Fig. 3 shows the characteristic of the flow rate $Q_{1}$ according to the electric power $P_{1}(t)$ of the motor-pump 1 (computing data and polynomial model). This curve is valid only for fixed hydraulic load by extrapolation from real pumps. The polynomial equation is as follows:

$Q_{1}=a_{4} \cdot P_{1}^{4}+a_{3} \cdot P_{1}^{3}+a_{2} \cdot P_{1}^{2}+a_{1} \cdot P_{1}+a_{0}$

where $\quad a_{i(i=0 . .4)}: \quad\left(a_{0}=-3 \mathrm{~m}^{3} / \mathrm{h}, \quad a_{1}=1.5 \mathrm{E}-02 \mathrm{~m}^{3} / \mathrm{h} / \mathrm{W}\right.$, $a_{2}=-1.5 \mathrm{E}-05 \mathrm{~m}^{3} / \mathrm{h} / \mathrm{W}^{2}, a_{3}=8 \mathrm{E}-09 \mathrm{~m}^{3} / \mathrm{h} / \mathrm{W}^{3}, a_{4}=-1.6 \mathrm{E}-12 \mathrm{~m}^{3} /$ $\left.\mathrm{h} / \mathrm{W}^{4}\right)$.

2.1.2.5. Water pumping and its desalination system. Freshwater production is achieved by using reverse osmosis (RO) membrane from the brackish water of tank 1 . So the motor-pump $P_{2}$ allows boosting the permeate (fresh) water flow which is collected in the tank 2 (see Fig. 1). In optimization goal, it is necessary to minimize the number of sizing parameters. So, a new compact model of the RO with the pump $P_{2}$ is developed in this paper requiring only one design parameter. The reverse osmosis (RO) membrane needs high pressure for the good operating of the RO. This pressure must exceed the osmotic pressure of the brackish water. The characteristic pressure/flow rate of the pump must be appropriate to the size of the RO membrane with the best energy efficiency. Thus, the size of the RO membrane was retained as the unique design parameter. This size, noted CMD (Cubic Meters per Day) in the paper, is defined as the nominal production capacity of freshwater per day $\left(\mathrm{m}^{3} / \mathrm{d}\right)$. Hydraulic load made by the RO membrane leads to a large variability of the pressure vs flow rate. Thus, the motorpump $P_{2}$, thanks to variable speed, can modulate the flow rate and hence the consumed electric power. With the help of WinCAPS software for pumps and ROSA software [30,31] for RO membrane (Filmtec), they

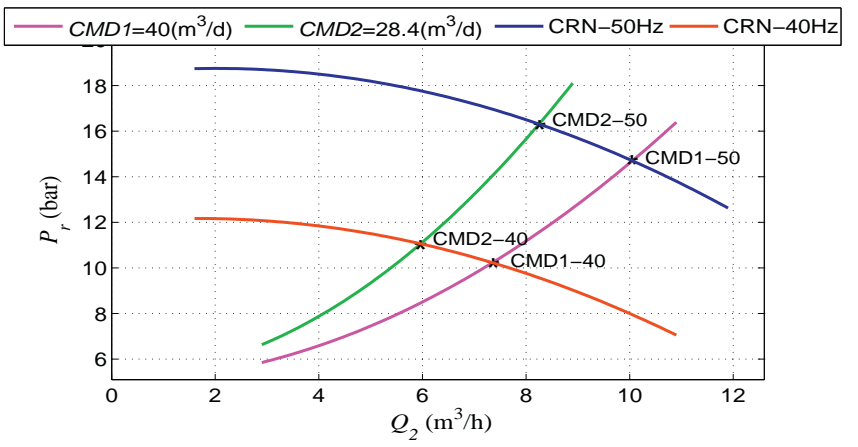

Fig. 4. Pressure vs flow rate $Q_{2}$ for CRN10-18 (GRUNDFOS-pump) at variable speed and two reverse osmosis membranes (CMD1 and CMD2).

Table 1

Some configurations using moto-pumps "CRN" of Grunfos and RO membrane "BW30" of Filmtec

\begin{tabular}{ll}
\hline Moto-pump of CRN type & RO membrane of BW30 type \\
\hline CRN1S-36 $(1.1 \mathrm{~kW})$ & BW30-2540 $\left(\mathrm{CMD}=3.2 \mathrm{~m}^{3} / \mathrm{d}\right)$ \\
CRN3-29 $(2.2 \mathrm{~kW})$ & BW30-4040 $\left(\mathrm{CMD}=9.1 \mathrm{~m}^{3} / \mathrm{d}\right)$ \\
CRN10-18 $(7.5 \mathrm{~kW})$ & BW30-330 $\left(\mathrm{CMD}=28.4 \mathrm{~m}^{3} / \mathrm{d}\right)$ \\
CRN10-18 $(7.5 \mathrm{~kW})$ & BW30-400 $\left(\mathrm{CMD}=40.0 \mathrm{~m}^{3} / \mathrm{d}\right)$ \\
\hline
\end{tabular}

allow us to calculate the hydraulic characteristics depending on the size for both and the speed for pumps. Fig. 4 shows hydraulic characteristic (pressure vs flow rate) for two sizes of the reverse osmosis membrane (CMD1 and CMD2) with the same pump CRN10-18 operating for two frequencies $(40 \mathrm{~Hz}$ and $50 \mathrm{~Hz})$. The intersection of the four curves leads to the operating points (CMD1-40, CMD1-50 and CMD2-40, CMD2-50).

Like for the pump 1, to optimize the size of the studied system, an equation between the size of the RO membrane (CMD), the flow rate $\left(Q_{2}\right)$ and the electric power $\left(P_{2}\right)$ has to be found. With WinCAPS and ROSA softwares, different combinations of pump-RO membrane can be defined with a good energy efficiency on a large scale by means of variable speed motor. Thus, Table 1 shows the selected combinations. Fig. 5 shows the results of these four combinations with the power supply frequency varying from $30 \mathrm{~Hz}$ to $50 \mathrm{~Hz}$.

With "Surface Fitting Tool" of Matlab, a custom model (10) can depict these four pump-RO membrane combinations. Fig. 5 shows the

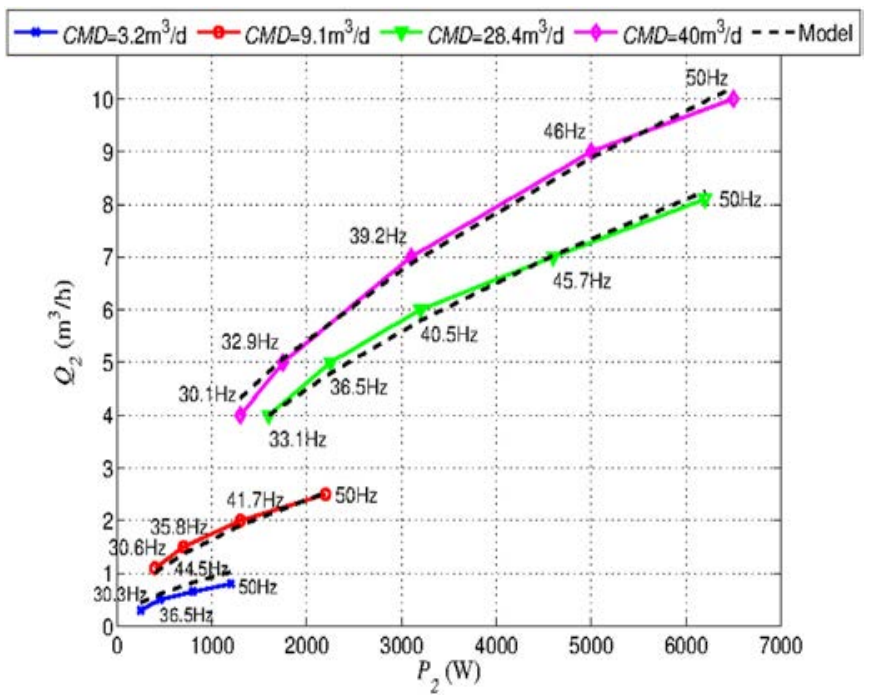

Fig. 5. Flow rate $Q_{2}$ vs electric power $P_{2}$ for four CRN pump-RO membrane combinations in variable power supply frequency and the $Q_{2}$ vs $P_{2}$ model (10). 
characteristic of the flow rate $Q_{2}$ according to the electric power $P_{2}$ of the motor-pump 2 (real data and the custom model). This curve is valid only for the optimal pump-RO membrane combinations from RO Filmtec membranes and real Danfos pumps supplied at variable frequency between $30 \mathrm{~Hz}$ and $50 \mathrm{~Hz}$. The equation linking the RO membrane $(C M D)$, the flow rate $\left(Q_{2}\right)$ and the electric power $\left(P_{2}\right)$ is as follows:

$Q_{2}=0.01224 \cdot P_{2}^{0.5341} \cdot C M D^{0.5525}$.

When the size of the RO membrane is fixed, the electric power depends on the supply frequency (speed) of the motor-pump. For operational frequency range $\left(f_{s}\right)$ between $30 \mathrm{~Hz}$ and $50 \mathrm{~Hz}$, the electric power has one operational range between $P_{2, \min }$ (for $f_{s}=30 \mathrm{~Hz}$ ) to $P_{2, \max }$ (for $f_{s}=50 \mathrm{~Hz}$ ) where:

$\left\{\begin{array}{l}P_{2, \min }=104.8 \cdot C M D^{0.6772} \\ P_{2, \max }=478.7 \cdot C M D^{0.7058}\end{array}\right.$.

To know the freshwater flow produced by the RO membrane, there is a recovery rate $R_{r}$ which depends of the RO membrane surface and the upstream flow rate. The relation of the recovery rate $R_{r}$ can be extrapolated as follows:

$R_{r}=0.1623 \cdot Q_{2}^{0.452} \cdot C M D^{-0.3535}$

with the recovery rate $R_{r}$ and the flow rate $Q_{2}$, the freshwater flow $Q_{2 p}$ and the concentrate flow $Q_{2 r}$ are calculated by the following relationships:

$\left\{\begin{array}{c}Q_{2 p}=R_{r} \cdot Q_{2} \\ Q_{2 r}=Q_{2}-Q_{2 p}\end{array}\right.$.

Consequently, with the Eqs. (10) to (13), we obtain the relation of the freshwater production $Q_{2 p}$ as function of the power $P_{2}$ and the size of the RO membrane as follows:

$Q_{2 p}=\left(3.25 \cdot 10^{-} 5 \cdot P_{2}+0.0264\right) \cdot C M D^{0.4636}$.

2.1.2.6. Water tanks. In our system, two storage tanks are used: one for storing the brackish water filled by the drawing pump 1, and a second for the freshwater produced by the desalination process (RO membrane + pump 2). The capacities of water tanks 1 and 2 depend on the surface area and height of the tanks. In the optimization process, the tank heights remain constant, and the surface areas will be considered as the design parameters. In dynamic operation, the storage capacity is proportional to the water level in the tank. For the tanks 1 and 2, these levels are noted $L_{1}$ and $L_{2}$, respectively. In dynamic operation, the level $L_{1}(t)$ is determined by the flow rates of the two pumps as follows:

$\left\{L_{1}(t)=L_{1}(t-\Delta t)+\frac{Q_{1}(t)-Q_{2}(t)}{S_{1}} \cdot \Delta t\right.$

In dynamic operation, the level $L_{2}(t)$ is determined by the permeate water flow $Q_{2 p}(t)$ from the RO membrane and the water consumed $Q_{\text {load-hydrau }}(t)$ as follows:

$\left\{L_{2}(t)=L_{2}(t-\Delta t)+\frac{Q_{2 p}(t)-Q_{\text {load-hydrau }}(t)}{S_{2}} \cdot \Delta t\right.$

with $\Delta t$ : sampling time step (h) and $S_{1}, S_{2}$ : surface areas of tank 1 and tank 2 respectively.

2.1.2.7. Freshwater and electricity loads. Electricity and freshwater consumption correspond to a family home. The electrical demand is defined over one week and repeated each week with seasonal modulation [18]. Fig. 6 shows the electrical power demand for a typical week. Freshwater demand is defined over one day and repeated each day [18]. Fig. 7 shows the water flow demand for a typical day.

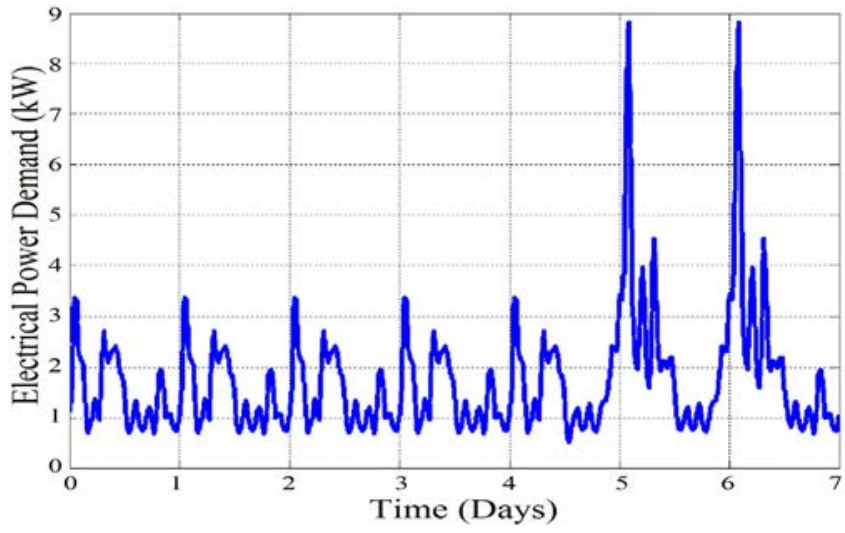

Fig. 6. Weekly electrical power consumption profile.

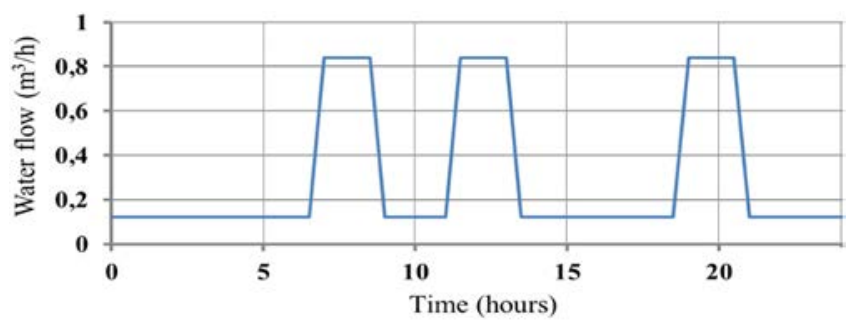

Fig. 7. Daily freshwater consumption profile.

\subsection{Resolution system}

In order to optimize the sizing of all the parameters of this system, it is necessary to solve the system in a real environment for one year, using a dynamic simulator. Weather profiles: wind speed $\left(V_{\text {wind }}\right)$, solar irradiation $\left(I_{r}\right)$ and ambient temperature $\left(T_{a}\right)$ must be known. The resolution system uses recording data from a typical region (North Tunisia) during one year with a acquisition time of half an hour. Before starting the optimization problem, the following paragraph defines two performance indicators $\left(L P S P_{E}\right.$ and $\left.L P S P_{H}\right)$ that are used in the criteria to be optimized and also in the constraints by limiting their values.

\subsubsection{Performance indicators}

2.2.1.1. Loss of electric Power Supply Probability $\left(\operatorname{LPSP}_{E}\right)$.

$\operatorname{LPSP}_{E}(\%)=100 \cdot \frac{\sum_{i=1}^{T_{s}}\left|\delta P^{i}\right| \cdot \Delta t}{\sum_{i=1}^{T_{S}} P_{\text {load-elec }}^{i} \cdot \Delta t}$

with $\delta P^{i}$ : electric power not delivered by the source to the load at the time $i$ during $\Delta t, P_{\text {load-elec }}^{i}$ : electric power consumed by the load at the time $i$ during $\Delta t, \Delta t$ : sampling time step (h).

2.2.1.2. Loss of hydraulic Power Supply Probability $\left(L P S P_{H}\right)$.

$\operatorname{LPSP}_{H}(\%)=100 \cdot \frac{\sum_{i=1}^{T_{s}}\left[Q_{\text {load-hydrau }}^{i} \cdot \Delta t\right]_{L_{2}^{i} \leq 0}}{\sum_{i=1}^{T_{s}} Q_{\text {load-hydrau }}^{i} \cdot \Delta t}$

with $Q_{\text {load-hydrau }}^{i}$ : flow of consumed water at the time $i$ during $\Delta t, L_{2}^{i} \leq 0$ : hydraulic failure when the tank 2 is empty during $\Delta t$.

\subsubsection{Dynamic simulator}

For each design parameter, it is necessary to calculate the powers evolution's involved $\left(P_{P V}(t), P_{W T}(t), P_{B a t}(t)\right)$, the state of the battery $(S O C(t))$, the water levels in each tank $\left(L_{1}(t), L_{2}(t)\right)$, the power of the motor-pumps $\left(P_{1}(t), P_{2}(t)\right)$ and the satisfaction or not to supply the electrical and hydraulic loads with a energy management. The energy management of such system constitutes itself a difficult issue which can 


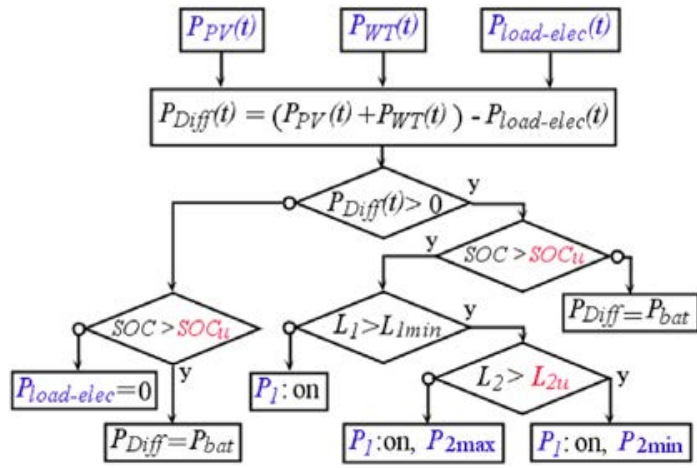

Fig. 8. Simplified management algorithm.

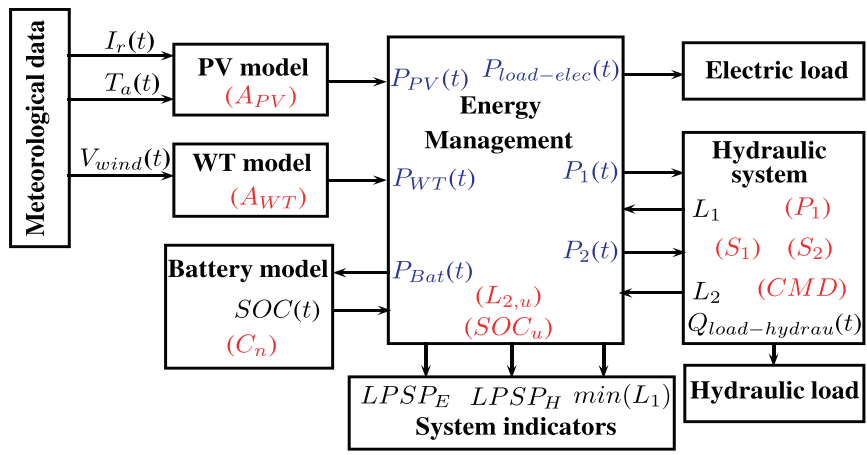

Fig. 9. Dynamic simulator with energy management.

be solved using optimal control methods. In this paper, a simple (rule based) but quite efficient energy management strategy developed in previous works [32] has been used. Fig. 8 shows the simplified principle of the management of the operation of the two motor-pumps $1\left(P_{1}\right)$ and $2\left(P_{2}\right)$ and the supply of the electric charge $\left(P_{\text {load - elec }}\right)$ according to the $S O C(t)$ of the battery compared to the $S O C_{u}$ and the water levels in the tanks (at the levels $L_{1, \min }$ and $L_{2, u}$ ). For more information, readers can refer to the paper [32]. For this purpose, a dynamic simulator (see Fig. 9) calculates the state of the system (all the variables listed above) and the system indicators $\left(\operatorname{LPSP}_{E}, \operatorname{LPSP}_{H}, \min \left(L_{1}\right)\right)$ over a year, with a sampling step, according to meteorological data (wind speed, irradiation, temperature) [18].

\subsubsection{Meta-models synthesis process}

In order to speed up the optimization system, meta-models are used to model the system in its specific environment. For this, the metamodeling by design of experiments (DOE) is efficient. The first step consists in creating a database of the outputs according to the inputs. This database is created with the dynamic simulator for simulated experiments. In order to avoid a huge database, the latin hypercube sampling (LHS) method is used to obtain only 5000 points [33] (with nine inputs, which are the decision variables displayed in Table 2).

Secondly, the goal is to find the best equation for each output according to the inputs in accordance with experiments. Thus, the "Model-Based Calibration" toolbox is used with equations of the Bspline form.

The meta-modeling process is summarized in Fig. 10 where $x_{i}$ denotes the decision variables, $y_{i}$ the dynamic simulator outputs and $\widehat{y_{i}}$ the meta-model outputs. The expressions are as follows:

$$
\left\{\begin{array}{c}
x_{i}=\left[A_{P V} ; A_{W T} ; C_{n} ; P_{1} ; C M D ; S_{1} ; S_{2} ; L_{2 u} ; S O C_{u}\right] \\
y_{i}=\left[L_{L P P_{H}}, L P S P_{E}, \min \left(L_{1}\right)\right] \\
\widehat{y_{i}}=\left[\widehat{L P S P_{H}}, \widehat{L P S P_{E}}, \widehat{\min \left(L_{1}\right)}\right]
\end{array} .\right.
$$

Table 2

Exploration range of decision variables.

\begin{tabular}{lll}
\hline Parameter & Minimum value & Maximum value \\
\hline$A_{P V}\left(\mathrm{~m}^{2}\right)$ & 20 & 100 \\
$A_{W T}\left(\mathrm{~m}^{2}\right)$ & 80 & 160 \\
$C_{n}(\mathrm{Ah})$ & 200 & 1400 \\
$P_{1}(\mathrm{~W})$ & 1500 & 2500 \\
$C M D\left(\mathrm{~m}^{3} /\right.$ day $)$ & 10 & 40 \\
$S_{1}\left(\mathrm{~m}^{2}\right)$ & 1 & 20 \\
$S_{2}\left(\mathrm{~m}^{2}\right)$ & 20 & 200 \\
$L_{2, u}(\mathrm{~m})$ & 0.3 & 1.9 \\
$S O C_{U}(\%)$ & 60 & 100 \\
\hline
\end{tabular}

\subsection{Optimization principle}

The goal consists in doing the co-optimization of the system sizing with an energy management. This involves two optimization nested loops. Firstly, the size of each element composing the photovoltaic/ wind system for the production of electricity and freshwater has to be determined: PV and wind turbine surfaces, nominal power of pumps, volume of tanks, battery capacity and RO membrane capacity. Secondly, for sharing energy storage between the battery and the freshwater tank, two intermediate levels of storage (one in the battery $\left(S O C_{u}\right)$ and the second in the freshwater tank $\left(L_{2 u}\right)$ ) are used by the energy management. This consists reserving enough in both storages for anticipating the lacking phases of renewable energy. To optimize the total embodied energy ( $E E$ ) of the system throughout its life cycle, it is necessary to define the cost model (MJ) of each element used. The next part gives these relations.

\subsubsection{Embodied energy modeling}

For the studied system (based on renewable energy), embodied energy is mainly consumed during elements manufacturing, on-site construction and decommissioning at end of life. Embodied energy consumed during the lifetime (maintenance) is relatively low, but taken account in the paper. The following paragraphs show the relationships of the $E E$ of each element of the studied system in terms of their design parameter.

2.3.1.1. Wind turbine. The embodied energy of wind turbine $E E_{W T}(\mathrm{MJ})$ is based on the swept area of the rotor $A_{W T}\left(\mathrm{~m}^{2}\right)$. The analytic relationship, coming from Ref. [34], is as follows:

$E E_{W T}=2360 \cdot A_{W T}+1875$.

2.3.1.2. Photovoltaic panels. The embodied energy of PV panel $E E_{P V}$ (MJ) is based on their surface area $A_{P V}\left(\mathrm{~m}^{2}\right)$. The analytic relationship, coming from Ref. [34], is as follows:

$E E_{P V}=3863 \cdot A_{P V}-47$.

2.3.1.3. Battery. The embodied energy of battery $E E_{B A T}(\mathrm{MJ})$ is based on its storage capacity $C_{n}(\mathrm{Ah})$ for the battery voltage of $12 \mathrm{~V}$. The analytic relationship, coming from Ref. [18], is as follows:

$E E_{B A T}=N_{r} \cdot 60 \cdot C_{n}$

with $N_{r}$ : number of battery replacement during the life cycle of the system.

2.3.1.4. Pumps. The embodied energy of motor-pumps $E E_{M P}(\mathrm{MJ})$ is based on their nominal electric power $P_{1 n}(\mathrm{~kW})$ and $P_{2 n}(\mathrm{~kW})$. The total for the two pumps with their supply converter, the analytic relationship coming from Ref. [34] is as follows:

$E E_{M P}=283 \cdot P_{1 n}+684 \cdot P_{2 n}+2200 \cdot\left(P_{C V 1}+P_{C V 2}\right)$

with $P_{C V} 1_{1}, P_{C V}$ 2: nominal power of supply converters feeding 


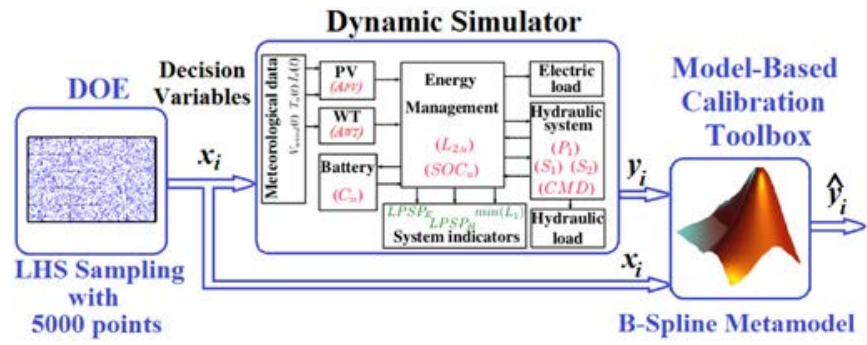

Fig. 10. Meta-modeling process.

respectively the motor-pumps $P_{1}$ and $P_{2}$ expressed in (kW).

Note: the nominal electric power of the motor-pump 2 is linked to the RO membrane sizing, thus $P_{2 n}$ is equal to $P_{2, \max }$ (Eq. (11)).

2.3.1.5. Tanks. The embodied energy of tanks $E E_{S T}$ (MJ) is based on their surface area $S_{1}$ and $S_{2}\left(\mathrm{~m}^{2}\right)$ and their height $h_{1}$ and $h_{2}$ (with $h_{1}=h_{2}=h=2 \mathrm{~m}$ ). The analytic relationship for the two tanks, coming from Ref. [34] is as follows:

$E E_{S T}=371 \cdot h \cdot\left(S_{1}+S_{2}\right)$.

2.3.1.6. Reverse osmosis membrane. The embodied energy of $\mathrm{RO}$ membrane $E E_{O I}(\mathrm{MJ})$ is based on its flow rate per day $C M D\left(\mathrm{~m}^{3} / \mathrm{d}\right)$. The analytic relationship of the RO membrane, taking account of the maintenance during all the life cycle, coming from Ref. [34] is as follows:

$E E_{O I}=5224 \cdot C M D$.

\subsubsection{Optimization problem}

In order to speed up the CPU time of the simulations performed over one year, a sampling time of $1 / 6 \mathrm{~h}$ is used. This "high" value may lead, in some configuration cases, to negative levels of water in the brackish water tank 1 . Instead of reducing this time step which would implies a significant increase of the CPU time, a constraint is added into the optimization problem ensuring $\min \left(L_{1}\right)>0$.

2.3.2.1. Definition. The optimization problem has three objectives to be minimized: $L P S P_{E}, L P S P_{H}$ and $E E$ under three constraints: $L P S P_{E}$ and $\operatorname{LPSP}_{H}$ less than $5 \%$ and the tank 1 never empty translated by min $\left(L_{1}\right)>0$, with nine decision variables $x_{i}$ (system parameters). The optimization problem may be expressed by the following equations: Optimization criteria:

$\min _{x_{i}}\left\{\begin{array}{c}F_{1}\left(x_{i}\right)=E E \\ F_{2}\left(x_{i}\right)=L P S P_{E} \\ F_{3}\left(x_{i}\right)=L P S P_{H}\end{array}\right.$

Constraints:

$G\left(x_{i}\right)=\left[\begin{array}{l}g_{1} \\ g_{2} \\ g_{3}\end{array}\right] \leq 0$

with

$g_{1}=L P S P_{E}-5 \% ; g_{2}=L P S P_{H}-5 ; g_{3}=-\min \left(L_{1}\right)$.

2.3.2.2. Algorithm. Genetic algorithms are well suited for solving this kind of problem. NSGA-II is classically used for multiobjective and constrained optimization cases $[35,36]$. In the following, the chosen parameters of the NSGA-II algorithm are two hundred individuals and five hundred generations.

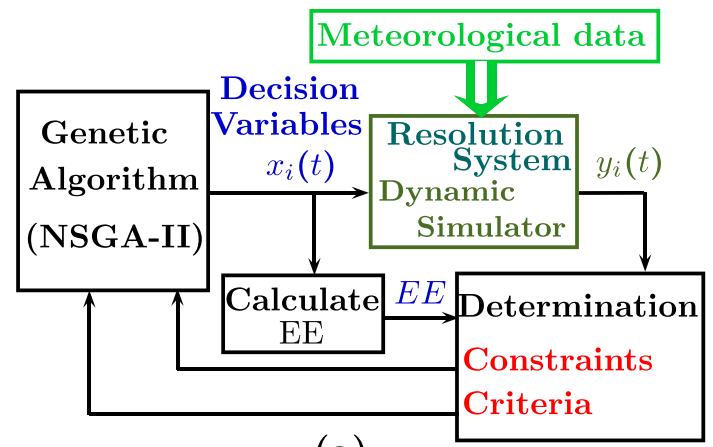

(a)

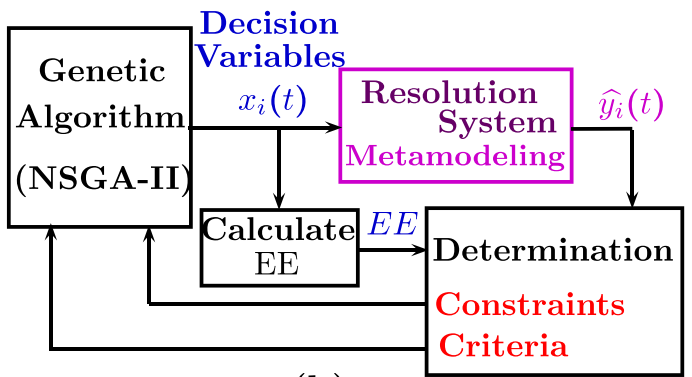

(b)

Fig. 11. Block diagram of the optimization process: (a) with Dynamic simulator, (b) with meta-modeling.

\subsection{Optimization process}

The system performance must be evaluated over long periods of time to take seasonal features and correlations of renewable energies into account. Two solutions are developed in this paper in order to optimize the studied system. First, the dynamic simulator is used for evaluations the constraints and criteria used by the NSGA-II algorithm. The simulator is run with all sampling points of one year $(52,560$ samples: 1 sample per $10 \mathrm{~min})$. Secondly, a meta-model is used for formulate the outputs of the studied system byparameterized equations for the decision variables. The sizing process by means of optimization is shown by Fig. 11.

\section{Results and discussions}

\subsection{Meta-model results}

With the DOE carried out with the dynamic simulator, the three indicators $\widetilde{y_{1}}=\widetilde{L P S P_{E}}, \widetilde{y_{2}}=\widetilde{L P S P_{H}}$ and $\widetilde{y_{3}}=\widetilde{\min \left(L_{1}\right)}$ defined in Fig. 10 are shown in Fig. 12. The red color cross clouds are the results of the dynamic simulator with 5,000 samplings (LHS) for the nine design parameters in the range given in Table 2. The dashed black line on each figure represent the best meta-model obtained with "model-based calibration" toolbox of Matlab. Globally, the meta-model curve is in the average of the point cloud for the useful zones ( $L P S P \geq 0$ and $L_{1, \min } \geq 0$ ). We also see that the point cloud for the $L P S P_{E}$ has a very low variance around its mean unlike the other two indicators.

\subsection{Sizing results}

The evolution of the dissatisfaction levels of the electric and hydraulic demands $L P S P_{E}$ and $L P S P_{H}$ according to the total embodied energy $E E$ over a 20-year life period is shown in Fig. $13\left(E E / L P S P_{E}, E E /\right.$ $L P S P_{H}$ and $L P S P_{E} / L P S P_{H}$ representations). This figure compares the three Pareto optimal solutions achieved from the meta-models optimization (noted by green color cross) and from the accurate solutions achieved by the dynamic simulator in the optimization loop (noted by 

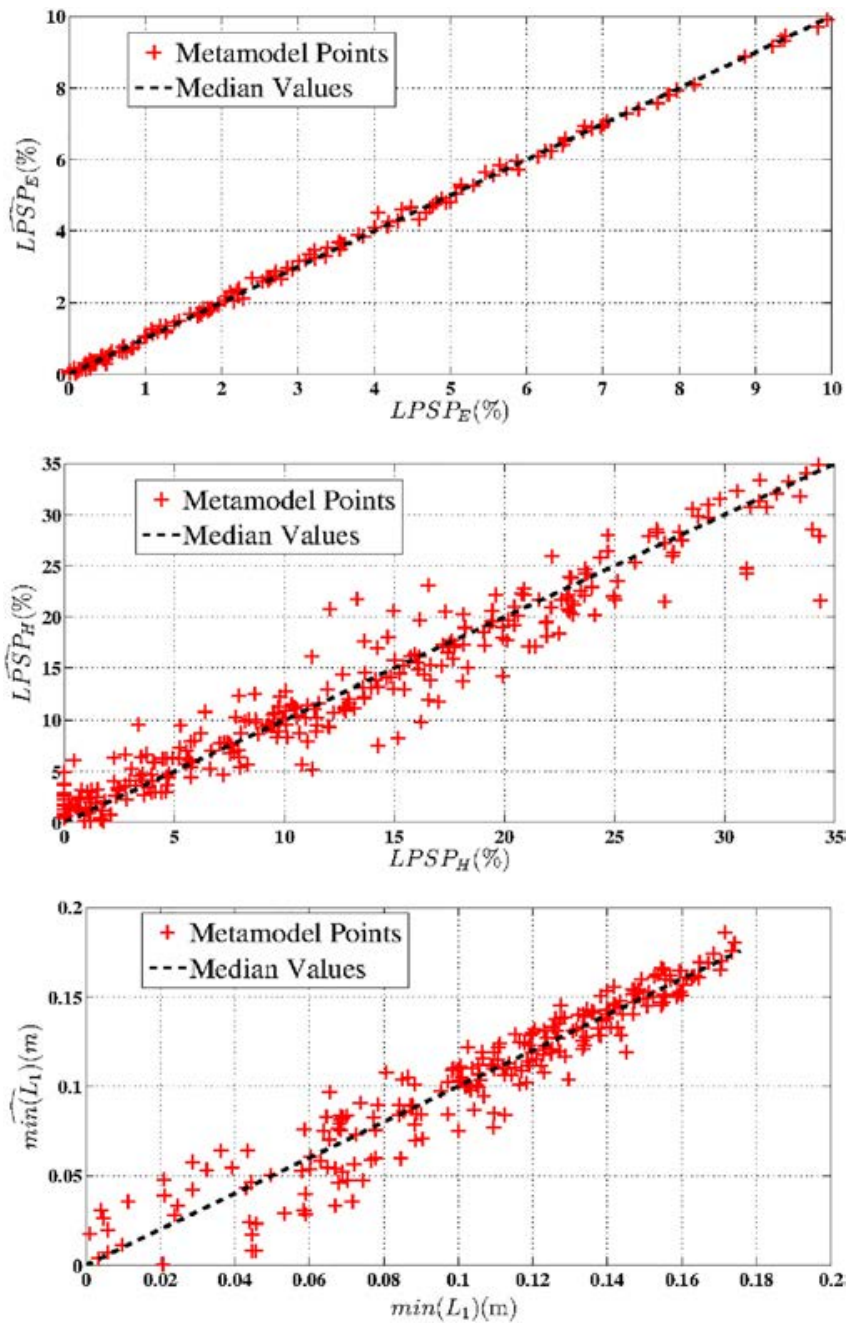

Fig. 12. Meta-model points for monitoring system indicators. (For interpretation of the references to color in this figure, the reader is referred to the web version of this article.) red color dot).

For the results with the meta-models, the indicators $L P S P_{E}$ and $L P S P_{H}$ have been recalculated with the dynamic simulator from the solutions of the sizing achieved with the NSGA-II algorithm (noted in Fig. 13: meta-model (recalculated solutions)). The figure shows only the solutions that respect the constraints (i.e. $L P S P_{E}<5 \%, L P S P_{H}<5 \%$ and $\min \left(L_{1}\right)>0$ ). We note a good match of solutions for the three Pareto diagrams. The results in the design space are shown in Fig. 14. The decision variables have globally comparable values. For example, taking in both cases the embodied energy of $8.4 \mathrm{E}+05 \mathrm{MJ}$, $L P S P_{E}=1.75 \%$ and $L P S P_{H}=1.84 \%$. Table 3 presents the obtained parameters for both models. This table shows the small difference between the parameters achieved by the dynamic simulator and those achieved by the meta-models. This shows the quality of the meta-model approximation even for this kind of complex system comprising two forms of storage (battery and water tank) and two kinds of loads (electricity and freshwater).

The results in the design space are shown in Fig. 14. The decision variables have globally comparable values. For example, taking in both cases the embodied energy of $8.4 \mathrm{E}+05 \mathrm{MJ}, L P S P_{E}=1.75 \%$ and $L P S P_{H}=1.84 \%$. Table 3 presents the obtained parameters for both models. This table shows the small difference between the parameters achieved by the dynamic simulator and those achieved by the metamodels. This shows the quality of the meta-model approximation even for this kind of complex system comprising two forms of storage (battery and water tank) and two kinds of loads (electricity and freshwater).

\subsection{CPU times results}

Table 4 shows the CPU time when the optimization is done using the dynamic simulator with all meteorological data and when the optimization is done using only the meta-models obtained with the processing explained in the paper in accordance with the same criteria and constraints.

\subsection{Discussions}

\subsubsection{Sizing results}

The results of Figs. 13 and 14 show that it is possible to have $L P S P_{E}$ and $L P S P_{H}$ almost zero but at the cost of a significant investment. An
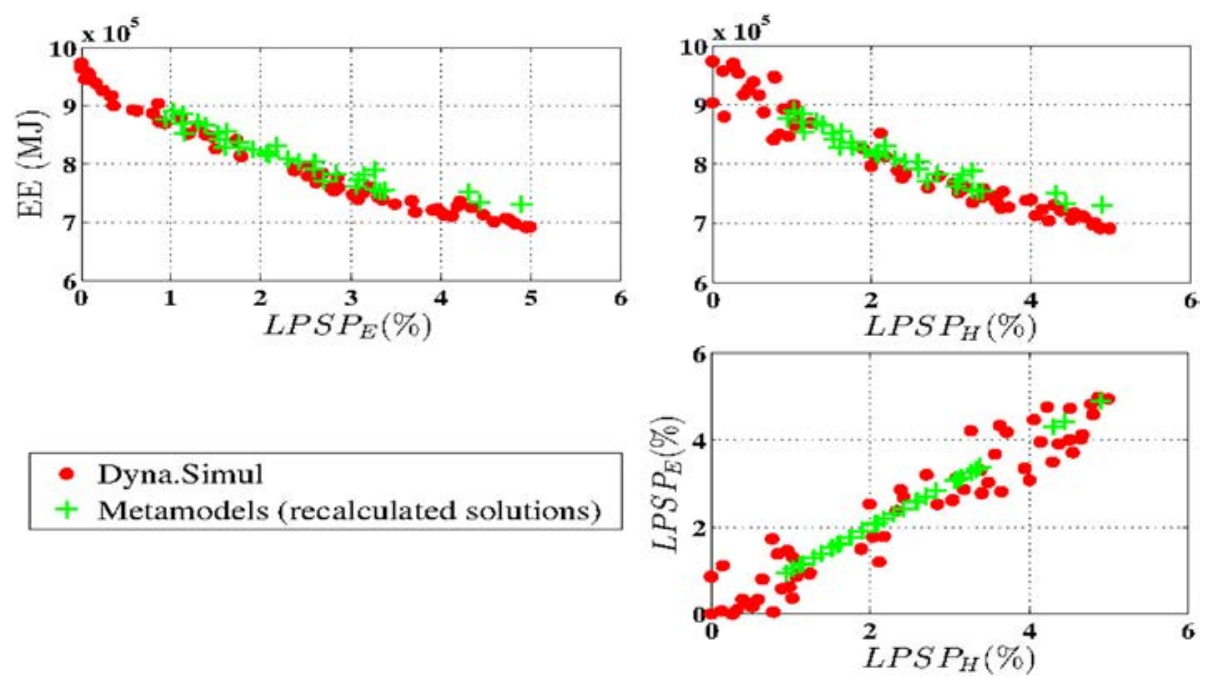

Fig. 13. Pareto optimal fronts for two simulation approaches: dynamic simulator and meta-model. (For interpretation of the references to color in this figure, the reader is referred to the web version of this article.) 

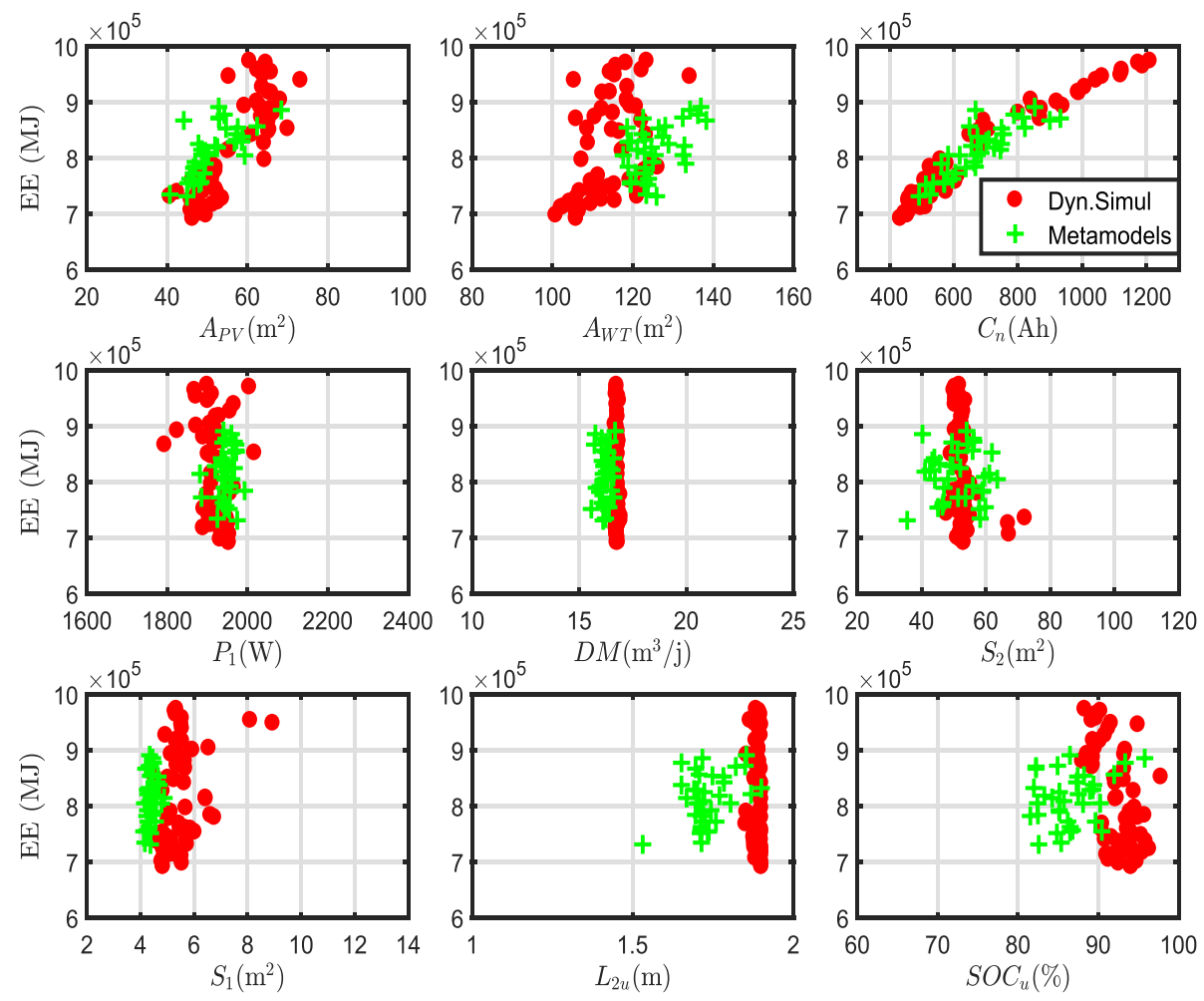

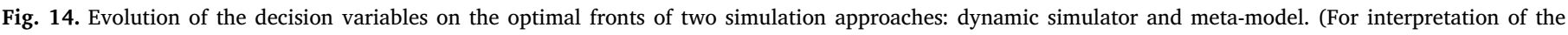
references to color in this figure, the reader is referred to the web version of this article.)

Table 3

Decision variables for $E E=8.4 \mathrm{E}+05 \mathrm{MJ}, L P S P_{E}=1.75 \%$ and $L P S P_{H}=1.84 \%$, with the dynamic simulator and with the meta-model.

\begin{tabular}{llll}
\hline Parameter & Dynamic simulator & Meta-model & Relative error \\
\hline$A_{P V}\left(\mathrm{~m}^{2}\right)$ & 61 & 58.7 & $-3.8 \%$ \\
$A_{W T}\left(\mathrm{~m}^{2}\right)$ & 123.3 & 127 & $+3 \%$ \\
$C_{n}(\mathrm{Ah})$ & 649.1 & 673 & $-3.7 \%$ \\
$P_{1}(\mathrm{~W})$ & 1926 & 1944 & $+0.9 \%$ \\
$C M D\left(\mathrm{~m}^{3} /\right.$ day) & 16.7 & 16.1 & $-3.6 \%$ \\
$S_{2}\left(\mathrm{~m}^{2}\right)$ & 52.3 & 43.3 & $-18.8 \%$ \\
$S_{1}\left(\mathrm{~m}^{2}\right)$ & 5.6 & 4.7 & $-16 \%$ \\
$L_{2, u}(\mathrm{~m})$ & 1.9 & 1.65 & $-13 \%$ \\
$S O C_{U}(\%)$ & 92.1 & 89 & $-3.4 \%$ \\
\hline
\end{tabular}

Table 4

CPU time NSGA-II optimization by using dynamic simulator or using the metamodels (with Processor AMD FX(tm), 8 cores, $4 \mathrm{GHz}$ ).

\begin{tabular}{|c|c|}
\hline Parameter & Value \\
\hline Number of parameters & 9 \\
\hline Number of criteria & 3 \\
\hline Number of constraints & 3 \\
\hline Number of run & 01 \\
\hline CPU time using the dynamic simulator & 72 h (3 days) \\
\hline CPU time using the meta-models & $0.22 \mathrm{~h}(13 \mathrm{~min})$ \\
\hline
\end{tabular}

investment reduction of $30 \%$ leads to an increase of $L P S P_{E}$ and $L P S P_{H}$ of only $5 \%$. The influence of the investment relates exclusively to PV and wind turbine surfaces and battery capacity. All the sizing of the hydraulic part and the control parameters remain insensitive to these investment variations, which is remarkable. It is the sizing of the battery that is the most sensitive, which triples value on the studied range. For PV and wind turbines, the variations are approximately proportional to the investments.
The percentage of relative error in Table 3 shows differences between the design parameters obtained with the meta-model of less than $4 \%$, except the size of the tanks that have a greater difference. This is due to a greater dispersion of the optimal points of the real $L P S P_{H}$ compared to the optimal points obtained by the meta-model; see in Fig. 12.

\subsubsection{CPU times}

The difference is made on the convergence time of the optimization algorithm. Three days are required with the dynamic simulator in the loop of the optimization algorithm and few minutes with the metamodels because for the dynamic simulator 52,560 samples are needed to calculate one optimization point, while for the meta-model-models the algorithm solves the equations once. Obviously, it is necessary to add one day to realize the database by DOE and the search of the metamodels from this database with a good representativeness.

\section{Conclusions}

This paper presents a methodology for the optimal sizing of a system for the production of fresh water and electricity, for an isolated site, with brackish water well, renewable energies and double storage in a battery and in water tanks (brackish water and fresh water). This approach is applied to the embodied energy $(E E)$ used over the total life cycle of the system. The hydraulic equations are extrapolated from the manufacturers catalogs of pump and reverse osmotic (RO) membrane. For the well pump, its flow is linked to the electrical power. The whole of the RO-based desalination unit, the freshwater flow rate was modeled according to the surface of the RO membrane and the electric power of the pump. Using meta-models in the optimization process saves CPU time with results similar to using a dynamic simulator (a few minutes for the first and several days for the second). The optimization results show that the cost of energy investment $(E E)$ is strongly related to the dissatisfaction of the production of water and electricity $\left(L P S P_{H}\right.$ 
and $L P S P_{E}$ ) with a non-linear behavior: a dissatisfaction of $5 \%$ saves $30 \% E E$. It is the size of the battery and the renewable energy sources that are sensitive to this economy. Furthermore, the total sizing of the hydraulic system is not linked to this economy.

\section{Acknowledgment}

The authors would like to thank the CMCU UTIQUE Program for financial support. This work was supported by the Tunisian Ministry of High Education and Research under Grant LSE-ENIT-LR 11ES15.

Appendix A. Quality parameters of brackish water and WHO requirements

\begin{tabular}{llc}
\hline Component & $\begin{array}{l}\text { Brackish water } \\
\text { (Southern Tunisia) }\end{array}$ & WHO* requirements \\
\hline PH & 7.8 & $\geq 6.5$ and $\leq 9.5$ \\
TDS (mg/l) & 5401 & $<1000$ \\
Sodium (mg/l) & 1430 & 200 \\
Potassium (mg/l) & 26.6 & 12 \\
Calcium (mg/l) & 320 & $<100$ \\
Magnesium (mg/l) & 106 & 50 \\
Bicarbonate (mg/l) & 167 & - \\
Chloride (mg/l) & 1900 & 250 \\
Sulfate (mg/l) & 1450 & 500 \\
Fluoride (mg/l) & 0 & 1.5 \\
Boron (mg/l) & 0 & 0.5 \\
\hline
\end{tabular}

* WHO: World Health Organization.

\section{References}

[1] E. Aleisa, K. Al-Shayji, Ecological-economic modeling to optimize a desalination policy: case study of an arid rentier state, Desalination (Elsevier) 430 (2018) 64-73.

[2] H. Kanchev, F. Colas, V. Lazarov, B. Francois, Emission reduction and economical optimization of an urban microgrid operation including dispatched PV-based active generators, IEEE Trans. Sustain. Energy 5 (4) (2014) 2163-2172.

[3] G. Mereia, C. Bergera, D.U. Sauer, Optimization of an off-grid hybrid PV-WindDiesel system with different battery technologies using genetic algorithm, Sol. Energy (Elsevier) 97 (2013) 460-473.

[4] N. Ghaffour, J. Bundschuh, H. Mahmoudi, M.F. Goosen, Renewable energy-driven desalination technologies: a comprehensive review on challenges and potential applications of integrated systems, Desalination (Elsevier) 356 (2015) 94-114.

[5] M. Gökçek, Ö.B. Gökçek, Technical and economic evaluation of freshwater production from a wind-powered small-scale seawater reverse osmosis system (WPSWRO), Desalination (Elsevier) 381 (2016) 47-57.

[6] R. Fornarelli, F. Shahnia, M. Anda, P.A. Bahri, G. Ho, Selecting an economically suitable and sustainable solution for a renewable energy-powered water desalination system: a rural Australian case study, Desalination (Elsevier) 435 (2018) $128-139$.

[7] A. Maleki, M.G. Khajeh, M.A. Rosen, Weather forecasting for optimization of a hybrid solar-wind-powered reverse osmosis water desalination system using a novel optimizer approach, Energy (Elsevier) 114 (2016) 1120-1134.

[8] L.A. de Souza Ribeiro, O.R. Saavedra, S.L. de Lima, J.G. de Matos, Isolated microgrids with renewable hybrid generation: the case of Lençóis Island, IEEE Trans. Sustain. Energy 2 (1) (2011) 1-11.

[9] H. Long, M. Eghlimi, Z. Zhang, Configuration optimization and analysis of a large scale PV/Wind system, IEEE Trans. Sustain. Energy 8 (1) (2017) 84-93.

[10] A. Arabali, M. Ghofrani, M. Etezadi-Amoli, M.S. Fadali, Stochastic performance assessment and sizing for a hybrid power system of solar/wind/energy storage, IEEE Trans. Sustain. Energy 5 (2) (2014) 363-371.

[11] G. Ma, G. Xu, Y. Chen, R. Ju, Multi-objective optimal configuration method for a standalone wind-solar-battery hybrid power system, IET Renew. Power Gener. 11 (1) (2017) 194-202.

[12] A. Maleki, Design and optimization of autonomous solar-wind-reverse osmosis desalination systems coupling battery and hydrogen energy storage by an improved bee algorithm, Desalination (Elsevier) 435 (2018) 221-234.

[13] A.S. de Ibarra, A. Milo, H. Gaztañaga, V. Debusschere, S. Bacha, Co-optimization of storage system sizing and control strategy for intelligent photovoltaic power plants market integration, IEEE Trans. Sustain. Energy 7 (4) (2016) 1749-1761.

[14] O. Dahmani, S. Bourguet, M. Machmoum, P. Guerin, P. Rhein, L. Josse, Optimization and reliability evaluation of an offshore wind farm architecture, IEEE Trans. Sustain. Energy 8 (2) (2017) 542-550.

[15] W. Peng, A. Maleki, M.A. Rosen, P. Azarikhah, Optimization of a hybrid system for solar-wind-based water desalination by reverse osmosis: comparison of approaches, Desalination 442 (2018) 16-31.

[16] E. Mayhorn, L. Xie, K. Butler-Purry, Multi-time scale coordination of distributed energy resources in isolated power systems, IEEE Trans. Smart Grid 8 (3) (2017) 998-1005.

[17] T. Layadi, G. Champenois, M. Mostefai, Modeling and design optimization of an autonomous multisource system under a permanent power-supply constraint, IEEE Trans. Sustain. Energy 6 (3) (2015) 872-880.

[18] D. Abbes, A. Martinez, G. Champenois, Life cycle cost, embodied energy and loss of power supply probability for the optimal design of hybrid power systems, ElsevierMath. Comput. Simul. 98 (2014) 46-62.

[19] R.H. Myers, D.C. Montgomery, C.M. Andersson-Cook, Response Surface Methodology: Process and Product Optimization using Designed Experiments, 3rd ed., (2009).

[20] P. Maussion, Design of Experiments in electrical engineering: applications in control and modeling, IEEE Workshop on Electrical Machines Design, Control and Diagnosis (WEMDCD), United Kingdom, 2017, pp. 179-186.

[21] M. Zaibi, T. Layadi, G. Champenois, X. Roboam, B. Sareni, J. Belhadj, A hybrid spline metamodel for photovoltaic/wind/battery energy systems, Renewable Energy Congress (IREC), 2015 6th International, 2015, pp. 1-6, , https://doi.org/ 10.1109/IREC.2015.7110909.

[22] W. Shepherd, D. Shepherd, Energy Studies, Imperial College Press, 2003.

[23] W. Tong, Wind Power Generation and Wind Turbine Design, WIT Press, 2010.

[24] J. Hofierka, J. Kaauk, Assessment of photovoltaic potential in urban areas using open-source solar radiation tools, Renew. Energy 34 (10) (2009) 2206-2214.

[25] B. Liu, S. Duan, T. Cai, Photovoltaic dc building module based bipv system: concept and design considerations, IEEE Trans. Power Electron. 26 (5) (2011) 1418-1429.

[26] F. Lasnier, T. Ang, Photovoltaic Engineering Handbook, Taylor and Francis, 1990.

[27] J. Copetti, F. Chenlo, Lead/acid batteries for photovoltaic applications. Test results and modelling, J. Power Sources 47 (1994) 109-118.

[28] Grandfos, Wincaps Software, (2017) http://www.industrialgines.com/en/wincaps7-43-grundfos/.

[29] Pumps software review, World Pumps (Elsevier) 394 (1999) 46-47.

[30] FilmTec releases ROSA Version 6.0, Membr. Technol. (Elsevier) 11 (2004) 3.

[31] F. Qaderi, E. Babanejad, Prediction of the groundwater remediation costs for drinking use based on quality of water resource, using artificial neural network, J. Clean. Prod. (Elsevier) 161 (September 10 2017) 840-849.

[32] M. Zaibi, G. Champenois, X. Roboam, J. Belhadj, B. Sareni, Smart power management of a hybrid photovoltaic/wind stand-alone system coupling battery storage and hydraulic network, Elsevier -Math. Comput. Simul. 146 (April 2018) 210-228.

[33] A. Olsson, G. Sandberg, O. Dahlblom, On Latin hypercube sampling for structural reliability analysis, Struct. Saf. 25 (1) (2003) 47-68

[34] H. Cherif, G. Champenois, J. Belhadj, Environmental life cycle analysis of a water pumping and desalination process powered by intermittent renewable energy sources, Elsevier - Renew. Sust. Energy Rev. 59 (June 2016) 1504-1513.

[35] N. Srinivas, K. Deb, Multiobjective function optimization using non-dominated sorting genetic algorithms, IEEE Trans. Evol. Comput. 2 (3) (1994) 221-228.

[36] M.A. Hozouri, A. Abbaspour, M. Fotuhi-Firuzabad, M. Moeini-Aghtaie, On the use of pumped storage for wind energy maximization in transmission-constrained power systems, IEEE Trans. Power Syst. 30 (2) (2015) 1017-1025. 